\title{
THE MALE OF MECYNOMETA GLOBOSA (O. P.-CAMBRIDGE) (ARANEAE, ARGIOPIDAE)*
}

\author{
By Arthur M. Chickering \\ Museum of Comparative Zoology
}

The female of this species was described from Guatemala by the elder Pickard-Cambridge in I889. Apparently it was known only from that part of Central America until Dr. Petrunkevitch reported a female specimen from the Wilcox camp on the San Lorenzo River in Panama in 1925. Mr. Banks reported two females from the Panama Canal Zone in 1929. I now have in my collection about two dozen females from several localities in the Canal Zone and El Valle, Panama. Only three males have appeared in the collection and all were collected in 1934 and 1936. Mecynometa is an interesting genus with a total of seven species now known. Simon described a species from the African Congo; five species have been described from South America; $M$. globosa (O. P.-Cambridge) is now known from two countries in Central America. Because males have hitherto been unknown I have thought it worth while to describe one of these in this brief paper.

\section{Mecynometa globosa (O. P.-Cambridge), I 889}

(Figures I-5)

Meta globosa O. P.-Cambridge, 1889

Argyroepeira globosa Keyserling, 1893

Mecynometa globosa Simon, 1894

$M$. globosa F. P.-Cambridge, 1903

$M$. globosa Petrunkevitch, 1911

M. globosa Petrunkevitch, 1925

M. globosa Banks, 1929

M. globosa Roewer, 1942

M. globosa Bonnet, 1957

Male. Total length $2 \mathrm{~mm}$. Carapace about $\mathrm{I} \mathrm{mm}$. long; about .8 $\mathrm{mm}$. wide between second and third coxae where it is widest; about $.4 \mathrm{~mm}$. tall; with median fovea a broad, shallow depression.

Eyes. Eight in two rows. Viewed from above, anterior row strongly recurved; posterior row only slightly so. Viewed from in front, anterior row almost straight; posterior row procurved, all measured by centers. Central ocular quadrangle as wide in front as behind; longer than wide in ratio of about II : IO. Ratio of eyes AME : ALE : PME : PLE $=7.5: 6: 7: 5$. LE somewhat angu-

\footnotetext{
* Manuscript received by the editor January 8, 1963.
} 

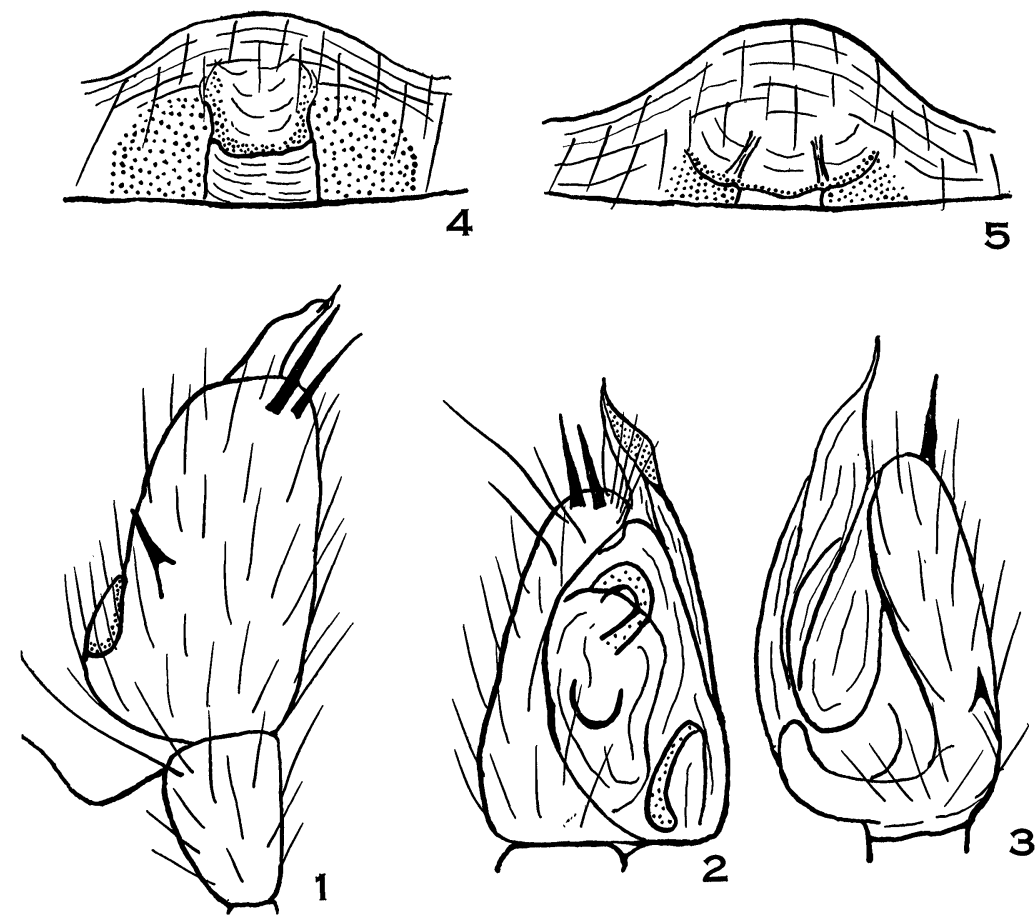

Figs. 1-5. External anatomy of Mecynometa globose. Fig. 1. Tarsus and tibia of left palp of male; dorsal view. Figs. 2-3. Two other views of same male palp. Figs. 4-5. Epigyna from two different specimens; as viewed from behind.

lar. AME separated from one another by about their diameter, from ALE by slightly more than their radius. PME separated from one another by slightly less than their diameter, from PLE by their diameter. Height of clypeus equal to a little less than the diameter of AME. A long, slender spinule lies ventral to the interval between $A M E$ and ALE on each side.

Chelicerae. Nearly vertical and parallel; moderately robust; basal segment about $.8 \mathrm{~mm}$. long; fang normal, regularly curved; fang groove with teeth but exact number and placement not determined because of fragility of specimen.

Maxillae. Parallel; fairly broad; quite normal in respect to the usual features; without special modifications.

Lip. Much broader than long; strongly rebordered; does not quite reach to middle of the maxillae. 
Sternum. Broadly scutiform; broader than long in ratio of about $8: 7$; with numerous stiff bristles; not continued between fourth coxae which are separated by a little less than their width.

Legs. I234. Width of first patella at "knee" .I $3 \mathrm{~mm}$., tibial index of first leg 3. Width of fourth patella at "knee" . I mm., tibial index of fourth leg 5 .

Femora Patellae Tibiae Metatarsi Tarsi Totals (All measurements in $\mathrm{mm}$. )

$\begin{array}{lrrrrrr}\text { I. } & 3.90 & .48 & 3.97 & 4.42 & \text { I.O4 } & \text { I3.8 I } \\ \text { 2. } & 2.93 & .44 & 2.55 & 3.06 & .9 \mathrm{I} & 9.89 \\ \text { 3. } & \mathrm{I} .43 & .24 & .84 & \text { I.10 } & .45 & 4.06 \\ \text { 4. } & 2.4 \mathrm{I} & .33 & \mathrm{I} .76 & \mathrm{I} .98 & .59 & 7.07 \\ \text { Palp } & .45 & .09 & . \mathrm{I} 4 & - & .44 & \text { I.I } 2\end{array}$

Legs well supplied with relatively long hairs. The few spines are long and slender. Some of the curled hairs on the fourth femora have been broken off but there appear to be two rows of eight or nine in each row; these are in longitudinal rather than oblique rows as seen in Leucauge and extend nearly throughout the proximal half of the prolateral surface of the segment.

Palp. Both patella and tibia are short as shown in the table above. The cymbium has three unusual spines, two near the distal end and one near middle. The most important features are shown in Figures I-3.

Abdomen. About I mm. long; only slightly overlapping the carapace; about $.8 \mathrm{~mm}$. wide near posterior end where it is widest; about $.8 \mathrm{~mm}$. tall; closely resembles the abdomen of the female.

Color in alcohol. Cephalothorax, legs, and mouth parts all yellowish white with variations. Grayish flecks occur on several parts but their distribution is too irregular for description. Abdomen: basically yellowish white; with many silvery flecks on the dorsolateral and lateral surfaces; the middorsal region is free from the silvery flecks; there is a relatively large silvery spot on each side on the posterior surface dorsal and lateral to the spinnerets, less conspicuous in the male than in the female but still distinctive; the whole posterior end is light grayish except for the silvery spots but is probably quite deeply colored in some males as in certain females in the collection; the venter is generally yellowish white with a conspicuous transverse spot near the middle which is composed of a group of bright silvery flecks.

Female. The fang groove has three relatively robust teeth on the 
promargin; the retromargin has four teeth, the first of which is relatively large, the other three smaller. The curled hairs on the fourth femora appear to be arranged in two longitudinal rows with twelve in each row. Published figures of the epigynum differ considerably. This has led me to make a rather careful examination of these organs on several specimens. I have noted considerable difference in the appearance of this organ in different individuals. Perhaps these differences can be attributed to variations in internal tension and degree of chitinization and development following the process of moulting. Figures 4 and 5 illustrate differences noted in two females among specimens in my collection.

Collection records. Both Pickard-Cambridges (1889-1903) and Keyserling ( 1893 ) gave Guatemala as the locality for the original specimens. In addition to the specimens reported by Petrunkevitch (1925) and Banks (1929) as cited in the introduction to this paper I can now report collection of the species as follows: numerous females from Barro Colorado Island, Frijoles, and the Canal Zone Experiment Garden, all in the Canal Zone; four specimens from El Valle, Panama. I also have a total of four males in the collection. One of these is from El Valle, Panama; the remaining three are from Barro Colorado Island, C. Z. The described male was taken in August, 1936. All specimens in my collection have been taken in July and August during my repeated collecting trips to the Canal Zone and other parts of Panama beginning in the summer of 1928.

\section{BIBLIOGRAPHY}

BANKS, NATHAN

1929. Spiders from Panama. Bull. Mus. Comp. Zool., 69:53-96, 4 pls. Bonnet, Pierre

1957. Bibliographia Araneorum. 2. 3me partie. Toulouse: Les Artisans de l'Imprimerie Douladoure.

Cambridge, O. P.-And F. P.-CAMbridge

1889-1903. Arachnida-Araneida. In: Biologia Centrali-Americana. Dulau \& Co. London.

Petrunkevitch, Alexander

1925. Arachnida from Panama. Trans. Conn. Acad. Arts and Sci., 27: 51-248.

Simon, EUGENE

1907. Arach. rec. par Fea sur la cote occid. d'Afrique I. Ann. Mus. Civ. Genova. $43: 218-323$, f. 1-3. 

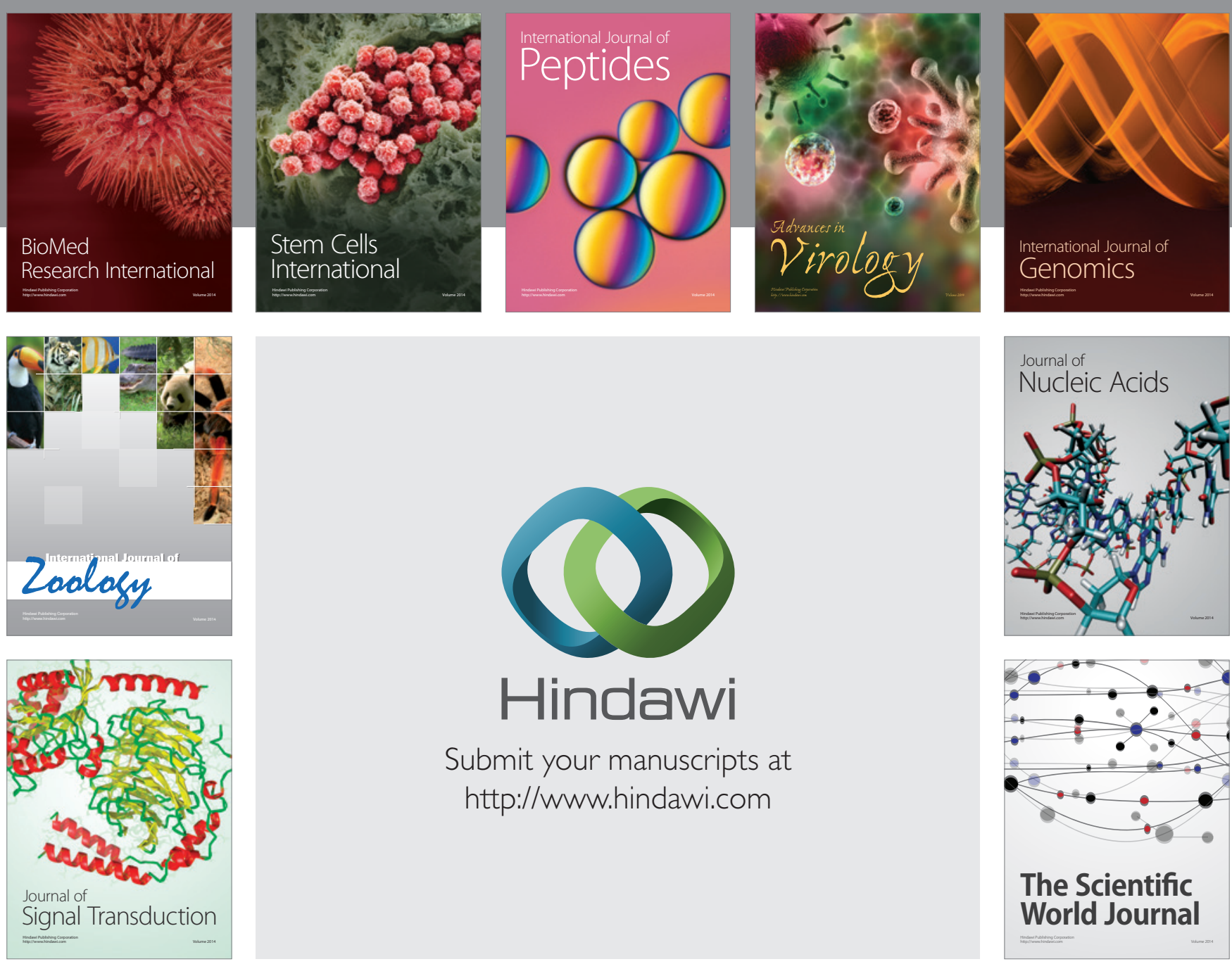

Submit your manuscripts at

http://www.hindawi.com
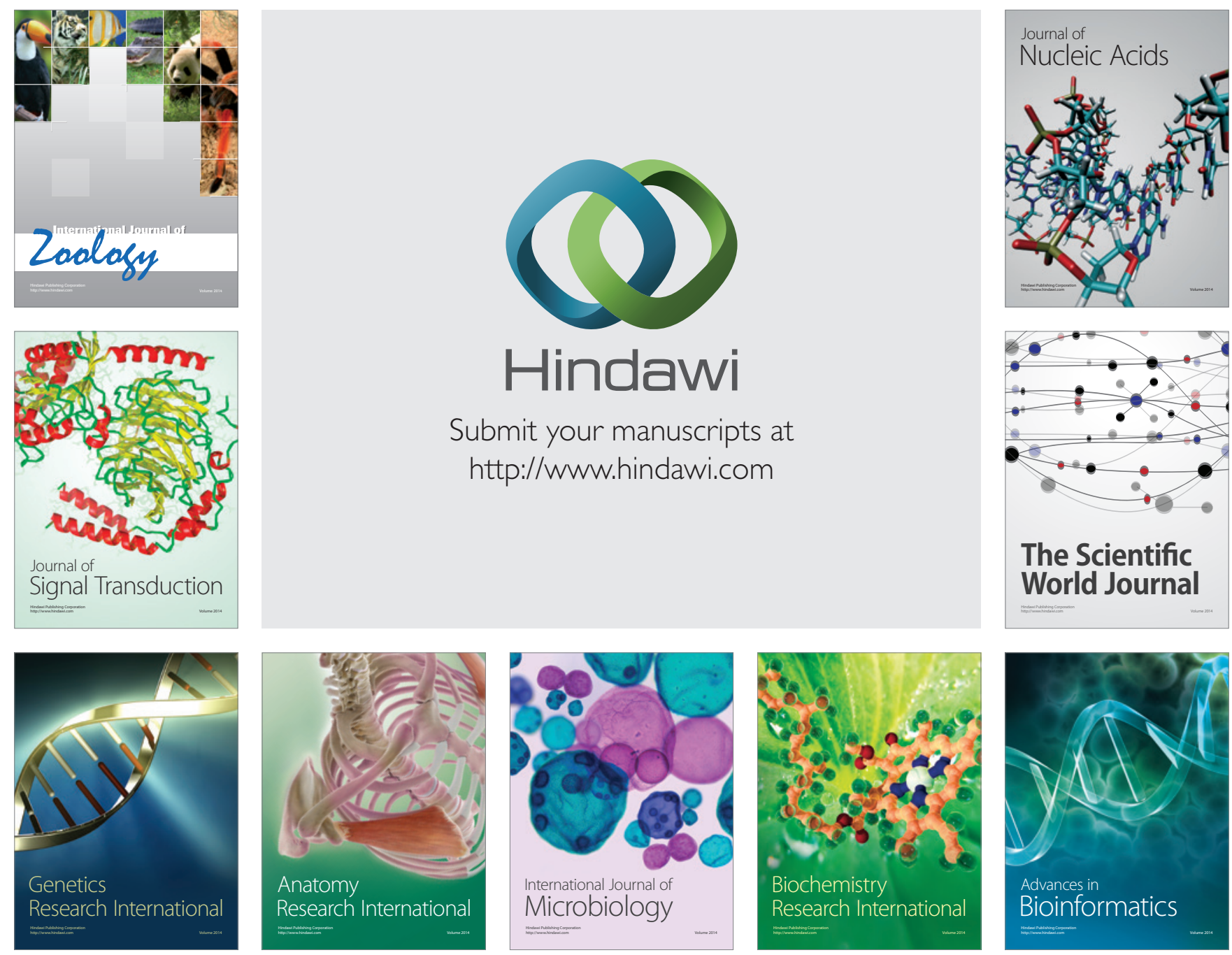

The Scientific World Journal
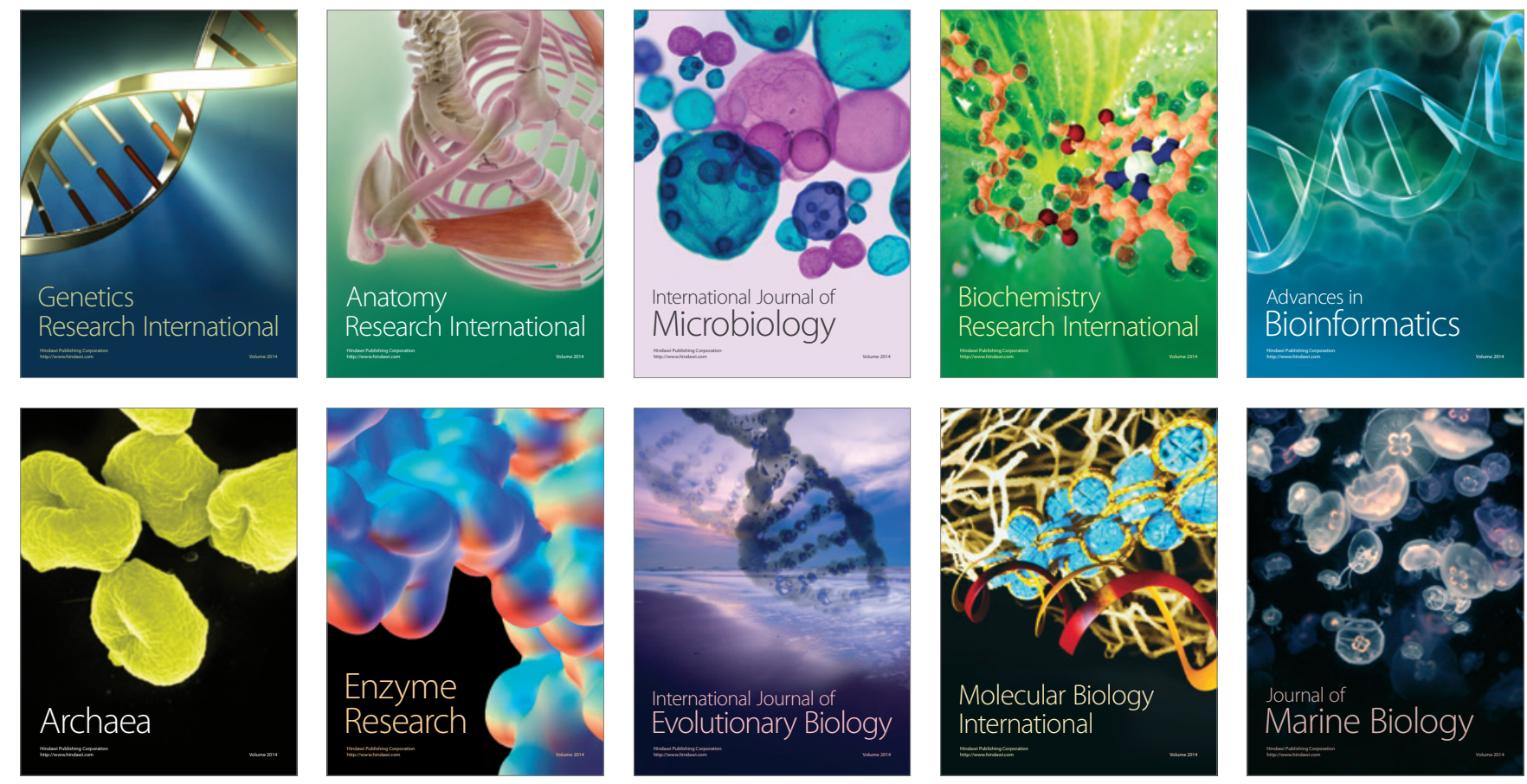